\title{
An oligopeptide transport gene from Candida albicans
}

\author{
Mark A. Lubkowitz, ${ }^{1}$ Loren Hauser, ${ }^{2}$ Michael Breslav, ${ }^{3}$ Fred Naider ${ }^{3}$ \\ and Jeffrey M. Becker ${ }^{1}$
}

\footnotetext{
1 Department of Microbiology and Department of Biochemistry, Cellular, and Molecular Biology, University of Tennessee, Knoxville, TN 37996-0845, USA

2 University of TennesseeOak Ridge Graduate School of Biomedical Sciences, Biology Division, Oak Ridge National Laboratory, Oak Ridge, TN 37831-8080, USA

3 Department of Chemistry, College of Staten Island, City University of New York, Staten Island, NY 10314, USA
}

\author{
Author for correspondence: Jeffrey M. Becker. Tel: +1 423974 3006. Fax: +1 4239744007. \\ e-mail: JBECKER@UTK.EDU
}

\begin{abstract}
A Candida albicans oligopeptide transport gene, OPT1, was cloned from a C. albicans genomic library through heterologous expression in the Saccharomyces cerevisiae di-/tripeptide transport mutant PB1X-9B. When transformed with a plasmid harbouring OPT1, S. cerevisiae PB1X-9B, which did not express tetra-/pentapeptide transport activity under the conditions used, was conferred with an oligopeptide transport phenotype, as indicated by growth on the tetrapeptide Lys-Leu-Leu-Gly, sensitivity to toxic tetra- and pentapeptides, and an increase in the initial uptake rate of the radiolabelled tetrapeptide Lys-Leu-Gly-[$\left.{ }^{3} \mathrm{H}\right]$ Leu. The level of oligopeptide transport was found to be influenced in the heterologous host by the source of nitrogen used for growth. The entire $3.8 \mathrm{~kb}$ fragment containing the oligopeptide transport activity was sequenced and an ORF of 2349 nucleotides containing a 58 nucleotide intron was identified. The deduced protein product of 783 amino acid residues contained 12 hydrophobic regions suggestive of a membrane transport protein. Sequence comparisons revealed that similar proteins are encoded by genes from S. cerevisiae and Schizosaccharomyces pombe and that OPT1 is not a member of the ABC or PTR membrane transport families.
\end{abstract}

Keywords: Candida albicans, peptide transport, Saccharomyces cerevisiae

\section{INTRODUCTION}

Peptide transport, a phenomenon defined as the translocation of peptides across the plasma membrane in an energy-dependent manner, has been well documented in bacteria, plants, fungi and mammals (for reviews see Becker \& Naider, 1995; Payne \& Smith, 1994). Upon internalization, peptides are quickly hydrolysed into their amino acid components to serve as sources of amino acids or nitrogen. In addition to acquiring nutrients from the environment, peptide transport has been shown to play a role in recycling cell wall peptides and in transducing signals for group behaviours such as sporulation and competency in Bacillus subtilis and chemotaxis in Escherichia coli. Recently, it has been proposed that in Salmonella typhimurium peptide transporters aid the bacteria in evading the host immune response by transporting membrane-disrupting peptides away from the plasma membrane (Parra-Lopez et al., 1993). Similarly, in Streptococcus pneumoniae the peptide transporters encoded by $p l p A$ and the amiA loci

The GenBank accession number for the nucleotide sequence reported in this paper is U60973. play a role in virulence by modulating adherence to epithelial and endothelial cells (Cundell et al., 1995).

Our laboratory has recently identified a family of di/tripeptide transporters named the PTR (Peptide TRansport) family. This family is characterized by several conserved motifs, has 12 putative transmembrane domains, and is driven by the proton-motive force. Members of the PTR family have been identified in a wide variety of eukaryotes and one prokaryote as well (Steiner et al., 1995). Well-characterized members of the PTR family are the di- and tripeptide transporters from Saccharomyces cerevisiae (ScPTR2; Perry et al., 1994) and from Candida albicans (CaPTR2; Basrai et al., 1995). Both CaPTR2 and ScPTR2 are regulated by the nitrogen source and are inducible by micromolar amounts of amino acids; the proteins they encode have broad substrate specificities with a preference for peptides containing hydrophobic residues (Basrai et al., 1992; Island et al., 1987). Prior to the establishment of the PTR family, all peptide transporters cloned were from prokaryotes and were members of the ATPbinding cassette (ABC) superfamily (Higgins, 1992). Recently, transporters from the PTR family have been 
identified in the prokaryote Lactococcus lactis (Hagting et al., 1994). However, in eukaryotes all peptide transporters thus far identified are members of the PTR family.

In addition to the di-/tripeptide transporter (CaPTR2) in C. albicans, three observations indicated the existence of another distinct peptide transport system. The first observation was that mutants resistant to the toxic peptide analogues bacilysin, polyoxin and nikkomycin $Z$ (all demonstrated substrates of the di-/tripeptide transport system) were able to transport tetra- and pentapeptides at wild-type levels, and, conversely, mutants resistant to various toxic tetrapeptides were able to transport dipeptides at wild-type levels (Payne \& Shallow, 1985; Milewski et al., 1988; McCarthy et al., 1985). Secondly, peptide-uptake experiments with radiolabelled compounds and chromophoric substrates demonstrated that dipeptides did not compete with tetra- and pentapeptides for entry into the cell, and vice versa tetra-and pentapeptides did not compete with labelled dipeptides (Milewski et al., 1988; McCarthy et al., 1985; Yadan et al., 1984). Thirdly, sensitivity to toxic di- and tripeptides was influenced by the nitrogen source and micromolar amounts of amino acids while sensitivity to toxic tetra- and pentapeptides was not regulated by similar means (Basrai et al., 1992). The conclusion from these studies was that $C$. albicans possessed two peptide transport systems: one for di- and tripeptides and another for oligopeptides. The size limitation of the oligopeptide transporter appeared to vary slightly from strain to strain, but in general tetraand pentapeptides were transported well and tripeptides were transported to a lesser extent (for review see Becker \& Naider, 1995). While the above studies provided strong physiological evidence for the presence of two peptide transport systems in C. albicans, final confirmation required genetic analysis. In an attempt to further define the molecular basis of peptide transport, we report here the cloning of a novel oligopeptide transporter gene from C. albicans that does not encode an ABC- or PTR-type transporter.

\section{METHODS}

Strains, vectors and media. The strains used in this study were S. cerevisiae PB1X-9B (MATa ura3-52 leu2-3,112 lys1-1 his438 ptr2-2) (Perry et al., 1994) and C. albicans SC5314 (Fonzi \& Irwin, 1993).

C. albicans and $S$. cerevisiae cells were maintained on YEPD medium $(2 \%, w / v$, dextrose; $1 \%, w / v$, yeast extract; $2 \%$, $\mathrm{w} / \mathrm{v}$, peptone; and $1.5 \%, \mathrm{w} / \mathrm{v}$, agar $)$. The minimal medium used for most studies was made by adding $10 \mathrm{ml} 10 \times$ filtersterilized YNB (Yeast Nitrogen Base; Difco) with ammonium sulfate and without amino acids to $90 \mathrm{ml}$ sterile water containing $2 \mathrm{~g}$ glucose and auxotrophic supplements (Sherman et al., 1986). For those experiments where proline was used as a sole nitrogen source, YNB without amino acids and without ammonium sulfate was supplemented with $0.1 \%$ proline. The mutant strain $S$. cerevisiae $\mathrm{PB} 1 \mathrm{X}-9 \mathrm{~B}$ was grown in Synthetic Complete medium (SC), which consisted of minimal medium with histidine, uracil, lysine and leucine. $S$. cerevisiae $\mathrm{PB} 1 \mathrm{X}-9 \mathrm{~B}$ transformed with pRS202-based plasmids was grown on SC lacking uracil (SC-Ura).

The C. albicans library used for cloning OPT1 was kindly provided by Gerry Fink (MIT, Boston, USA) (Liu et al., 1994). The library was created by partially digesting C. albicans strain 1006 genomic DNA (Goshorn \& Sherer, 1989) with Sau3A and cloning the resulting fragments $(>4 \mathrm{~kb})$ into the SalI site of pRS202, a URA3/2 $\mu$-based plasmid (Christianson et al., 1992).

Peptide medium consisted of minimal medium supplemented with auxotrophic requirements minus the amino acid leucine plus $100 \mu \mathrm{M}$ of one of the following peptides: Lys-Leu (KL), Lys-Leu-Gly (KLG), Lys-Leu-Leu-Gly (KLLG), Lys-Leu-GlyLeu (KLGL) or Lys-Leu-Leu-Leu-Gly (KLLLG). Abbreviations for toxic peptides and amino acids used in this study are as follows: ethionine, Eth; Ala-Eth, AEth; Leu-Eth, LEth; Lys-Leu-Eth, KLEth; Lys-Leu-Leu-Eth, KLLEth; Lys-LeuAla-Eth, KLAEth; and Lys-Leu-Leu-Leu-Eth, KLLLEth. All amino acids were in the $L$ configuration.

Enzymes, chemicals and reagents. Restriction endonucleases, T4 DNA ligase, T4 DNA polymerase and alkaline phosphatase were purchased from New England BioLabs or Promega and were used according to the manufacturers' specifications.

Synthesis of radioactive Lys-Leu-Gly- $\left[{ }^{3} \mathrm{H}\right]$ Leu (KLG-[ $\left[{ }^{3} \mathrm{H}\right] \mathrm{L}$ ). KLGL was prepared by conventional automated solid-phase peptide synthesis on an Applied Biosystems model 433A synthesizer. The peptide was cleaved from the resin with trifluoroacetic acid (TFA) and purified using a $\mathrm{C}_{18}$ reversedphase column $(19 \times 300 \mathrm{~mm})$ to $>99 \%$ homogeneity with a $5-20 \%$ linear gradient of acetonitrile in water over $60 \mathrm{~min}$. The product was verified using mass spectrometry $\left[\left(M^{+}+1\right)\right.$ $=430 \cdot 2$; calculated $=429 \cdot 6]$.

KLG- $\left[{ }^{3} \mathrm{H}\right] \mathrm{L}$ was prepared by solution-phase peptide synthesis as follows. BOC-Lys(BOC)-Leu-Gly-OH $(5 \cdot 2 \mathrm{mg} ; 10 \mu \mathrm{mol})$

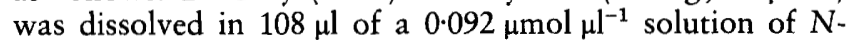
hydroxysuccinimide $(10 \mu \mathrm{mol})$ in dry dioxane. Dicyclohexylcarbodiimide $(10 \mu \mathrm{mol}$ in $57 \mu \mathrm{l})$ in dry dioxane was added and the reaction mixture was stirred for $1 \mathrm{~h}$ at ambient temperature. Leu $(0.65 \mathrm{mg} ; 5 \mu \mathrm{mol})$, dissolved in $1 \mathrm{ml}$ water, was added to radioactive leucine [American Radiolabelled Chemicals; specific activity $60 \mathrm{Ci} \mathrm{mmol}^{-1}\left(2 \cdot 22 \mathrm{TBq} \mathrm{mmol}^{-1}\right)$; concentration $1 \mathrm{mCi} \mathrm{ml}^{-1}$ ( $\left.37 \mathrm{MBq} \mathrm{ml}^{-1}\right)$ in $2 \%$ ethanol]. This solution was evaporated to dryness, redissolved in $250 \mu \mathrm{l}$ water/dioxane $(4: 1, \mathrm{v} / \mathrm{v})$ containing $N$-methylmorpholine $(50 \mu \mathrm{mol})$ and the solution containing the activated tripeptide was added. The resulting reaction mixture was stirred for $6 \mathrm{~h}$ at ambient temperature, $5.5 \mathrm{ml}$ TFA was then added, and after $5 \mathrm{~min}$ the reaction mixture was evaporated to dryness. The residue was redissolved in $500 \mu \mathrm{l}$ water, injected onto a Waters $\mu$ Bondapack $\mathrm{C}_{18}$ column $(7 \cdot 8 \times 300 \mathrm{~mm})$ and eluted isocratically using $5 \%$ acetonitrile in water, containing $0.025 \%$ TFA. Product eluting at the KLGL position was collected, evaporated, redissolved in water $(200 \mu \mathrm{l})$ and analysed by HPLC and on silica thin layers using a butanol/acetic acid/water (4:1:5, by vol.) mobile phase. TLC plates were exposed to film overnight at $-80^{\circ} \mathrm{C}$ and developed to show one radioactive spot with the mobility of the desired tetrapeptide. KLG- $\left[{ }^{3} \mathrm{H}\right] \mathrm{L}$ was $>97 \%$ pure according to HPLC. Specific radioactivity was $90 \mathrm{mCi} \mathrm{mmol}^{-1}\left(3.33 \mathrm{GBq} \mathrm{mmol}^{-1}\right)$. The peptide was diluted with nonradioactive KLGL as required.

DNA manipulations. Small-scale plasmid DNA preparations from $E$. coli transformants were performed as described in Sambrook et al. (1989). Plasmid DNA from S. cerevisiae 
transformants was isolated as described previously by Ward (1990). Whole-cell DNA from C. albicans was obtained by the procedure described by Ausubel et al. (1990).

Yeast transformations were done using the procedure described by Gietz et al. (1991) and plates were incubated at $30^{\circ} \mathrm{C}$ for $4 \mathrm{~d}$ or longer.

For Southern analyses, whole-cell DNA was digested with restriction enzymes and electrophoresed on $1.0 \%$ agarose gels. Southern blotting was done as described in Sambrook et al. (1989). Hybridization was performed at $60^{\circ} \mathrm{C}$ for $12 \mathrm{~h}$ in a Hybritube (Gibco-BRL) followed by two washes of $1 \times$ SSC $/ 0.1 \%$ SDS at $42{ }^{\circ} \mathrm{C}$ and two washes of $0.1 \times$ SSC $/ 0.1 \%$ $\mathrm{SDS}$ at $60^{\circ} \mathrm{C}$. The probe used for Southern blots was generated via PCR using the primers LC2 (5' GCATGGATTGTTCCTGACTGG $3^{\prime}$ ) and FT2 (5' CCAATACCAAACAAATGAGGC $\left.3^{\prime}\right)$. The product was $408 \mathrm{bp}$ in length and its position within the OPT1 ORF is depicted in Fig. 1. The Southern blot displayed in Fig. 2 was processed using the program Adobe Photoshop.

For plasmid-curing experiments, $S$. cerevisiae transformants were grown nonselectively in YEPD broth for about 40 generations. Cells were then plated on YEPD plates to obtain isolated colonies, which were picked, washed with water, resuspended at $5 \times 10^{6}$ cells ml $\mathrm{m}^{-1}$ in sterile water and spotted onto the appropriate peptide medium.

The nucleotide sequence of the $3.8 \mathrm{~kb}$ insert in plasmid pOPT1 was generated through automated cycle sequencing using an $\mathrm{ABI}$ 373A automated sequencer (Smith et al., 1986). The insert of pOPT1 was digested with either TaqI or Sau3A, subcloned into $\mathrm{M} 13$, and ssDNA was isolated as a template for sequencing from randomly chosen plaques. The sequenced fragments were assembled using the software DNASTAR and the remaining gaps were filled using properly placed primers. Primers were purchased from Bioserve Biotechnologies. Final assembly was performed using Autoassembler from ABI.

Growth and transport assays. Growth assays to determine the phenotype of the cells were done as described by Island et al. (1991). Briefly, $3 \mu \mathrm{l}$ culture from a suspension of $5 \times 10^{6}$ cells $\mathrm{ml}^{-1}$ was spotted onto the surface of the medium and plates were incubated at $30^{\circ} \mathrm{C}$ for 4-7 d.

Uptake of KLG- $\left[{ }^{3} \mathrm{H}\right] \mathrm{L}$ was determined using a protocol for uptake of dipeptides as described by Basrai et al. (1995) with a few modifications. S. cerevisiae cultures were grown overnight to exponential phase in SC-Ura medium. Cells were harvested by centrifugation, and resuspended in $2 \%$ glucose at a cell density of $2 \times 10^{8}$ cells $\mathrm{ml}^{-1}$. Cell suspension $(250 \mu \mathrm{l})$ was added to an equal volume of an uptake assay reaction mixture and incubated at $30^{\circ} \mathrm{C}$. The final concentrations of the components in the uptake assay solution were: $2 \%(\mathrm{w} / \mathrm{v})$ glucose; $10 \mathrm{mM}$ sodium citrate/potassium phosphate buffer (pH 5.0); and $\mathrm{KLG}-\left[{ }^{3} \mathrm{H}\right] \mathrm{L}[150 \mu \mathrm{M} ; 8.5 \mathrm{mCi}$ $\left.\mathrm{mmol}^{-1}\left(314.5 \mathrm{MBq} \mathrm{mmol}^{-1}\right)\right]$. Competition experiments were done in the presence of either $1.5 \mathrm{mM} \mathrm{L}, \mathrm{KL}, \mathrm{KLG}, \mathrm{KLLG}$ or KLLLG. At various time-points, $90 \mu \mathrm{l}$ portions were removed and filtered through a membrane. The yeast cells retained on the filter were washed twice with ice-cold distilled water, once with room temperature distilled water, and the residual radioactivity was measured by liquid scintillation. There was no peptide adsorption to the cell surface or sticking to filters since at $0^{\circ} \mathrm{C}$ the counts were at background level. The uptake results, calculated on the basis of $50 \%$ counting efficiency (determined using L- $\left[{ }^{3} \mathrm{H}\right]$ lysine as a standard, and the specific activity of the peptide), were expressed as nmol peptide uptake $\min ^{-1}(\mathrm{mg} \text { cell dry weight })^{-1}$.
Sensitivity assays. Sensitivity to ethionine, a toxic methionine analogue, and ethionine-containing peptides was determined by the method described by Island et al. (1987). Cells were grown overnight to the exponential phase of growth in SC, washed, and then resuspended at $5 \times 10^{6}$ cells $\mathrm{ml}^{-1}$ in sterile water. One millilitre of this cell suspension was added to $3 \mathrm{ml}$ molten Noble agar $(0.8 \%$ final concentration) and overlaid on $20 \mathrm{ml}$ of the same medium used to prepare the inoculum. A disk (6 mm diameter; Difco) was placed on the plate and $0.38 \mu \mathrm{mol}$ of each of the compounds to be tested was applied to the disks. Zones of inhibition were measured after $24-48 \mathrm{~h}$ incubation at $30^{\circ} \mathrm{C}$. Each test comprised at least three independent assays and the results represented in the Tables are means of the values obtained. Maximum variation between the zones of inhibition measured for each test was $\leqslant 3 \mathrm{~mm}$. A value of $7 \mathrm{~mm}$ for the diameter of the zone of inhibition represents a minimal growth inhibition value as the disk diameter was $6 \mathrm{~mm}$. Photodocumentation of sensitivity assays was done with a Umax Scanner and processed by Adobe Photoshop.

\section{RESULTS \\ Cloning of an oligopeptide transporter}

We have recently cloned di- and tripeptide transporters of C. albicans (CaPTR2) (Basrai et al., 1995) and Arabidopsis thaliana (AtPTR2-A and AtPTR2-B) (Steiner et al., 1994; Song et al., 1996) through heterologous expression in $S$. cerevisiae. Unlike C. albicans, $S$. cerevisiae has been found to transport only a limited number of tetra- and pentapeptides under a limited number of growth conditions (reviewed by Becker $\&$ Naider, 1995). Therefore, as our primary screen, we transformed the $S$. cerevisiae di-/tripeptide transport mutant PB1X-9B with a high copy number C. albicans genomic library and screened for the ability of $S$. cerevisiae to grow on a normally nonutilized tetrapeptide as a sole source of auxotrophic supplements.

A pRS202-based C. albicans genomic library was transformed into $S$. cerevisiae PB1X-9B and 32000 $U R \mathrm{A3}^{+}$transformants were obtained. Transformants were pooled into six groups of approximately 5200 transformants each and subsequently plated onto a medium containing $50 \mu \mathrm{M}$ KLLG as the sole source of leucine and lysine and ammonium sulfate as a nitrogen source. A double auxotrophic selection was employed to preclude the possibility of cloning the C. albicans LEU2 or LYS1 homologues. S. cerevisiae PB1X-9B cannot utilize the tetrapeptide KLLG as a sole source of lysine or leucine when grown on a medium containing a rich nitrogen source such as ammonium sulfate (unpublished observation). Oligopeptide-transport (OPT)-positive colonies appeared after $5-7 \mathrm{~d}$ incubation at $30^{\circ} \mathrm{C}$.

Curing of the plasmid by growth in nonselective conditions as well as shuttling the plasmid through $E$. coli and back into $S$. cerevisiae PB1X-9B demonstrated that the OPT activity was plasmid-borne. Subsequently, two different plasmids, denoted pOPT1 and pOPT24, containing inserts of 3.8 and $4.3 \mathrm{~kb}$, respectively, were recovered from a representative sample of $\mathrm{OPT}^{+}$colonies. Initial restriction mapping demonstrated that the 


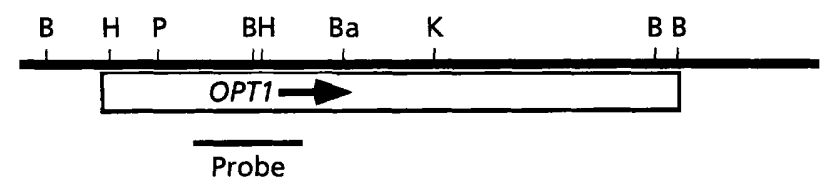

$200 \mathrm{bp}$

Fig. 1. A partial restriction map of the $3.8 \mathrm{~kb}$ fragment from POPT1. The location and orientation of the ORF are indicated as well as the location of the probe used in Southern blots. Restriction sites are as follows: B, BstXI; H, Hincll; P, Pvull; Ba, BamHI; K, Kpni.

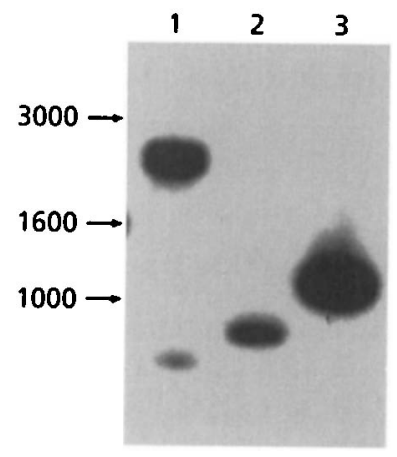

Fig. 2. Southern blot. Analysis of hybridization of a probe of OPT1 to genomic DNA isolated from C. albicans SC5314 was performed as described in Methods. Lanes: 1, Hincll digest; 2, Pvull-BamHI digest; 3, Pvull-Kpnl digest. Size markers are in bp.

smaller of the two plasmids, pOPT1, overlapped entirely with the larger plasmid, pOPT24. Therefore, the plasmid pOPT1 (Fig. 1) was used in all subsequent experiments.

\section{Southern blotting}

Southern blot analysis was done to ensure that OPT1 was derived from $C$. albicans genomic DNA and to determine if there were other homologous genes. Genomic DNA was isolated from C. albicans SC5314 and digested with the restriction enzymes HinclI, BamHI/PvuII and PvuII/KpnI. The resulting fragments were separated on a $1 \%$ agarose gel and Southern blotting was performed as described in Methods. The $P v u \mathrm{II}-K p n \mathrm{I}$ and PvuII-BamHI digests were each predicted to yield one band while the HincII digest was predicted to yield two bands. As seen in Fig. 2, each digest produced their predicted bands: bands of $617 \mathrm{bp}$ and $>2700 \mathrm{bp}$ for Hincll (lane 1), $790 \mathrm{bp}$ for PvulIBamHI (lane 2) and 1163 bp for PvuII-KpnI (lane 3).

\section{Nucleotide and deduced amino acid sequence of OPT1}

Sequence analysis revealed the presence of two ORFs, separated by a type II intron, and encoding a hydrophobic protein of 783 amino acids with an apparent molecular mass of $88 \mathrm{kDa}$ and a $\mathrm{pI}$ of $7 \cdot 1$ (Fig. 3). The first ORF contained 1626 nucleotides while the second ORF contained 723 nucleotides excluding the stop codon. The intron separating the two ORFs was 58 nucleotides in length and contained the highly conserved $5^{\prime}$ splice site (GCATGT), 3' splice site (TAG) and branch point (TACTAAC) (Rymond \& Rosbash, 1992). The two ORFs and intron constitute the gene OPT1. The size and hydrophobic nature of the predicted protein product of OPT1 are suggestive of a membranebound protein with at least 12 putative transmembrane domains of 20-24 amino acid residues.

A search of the database using the BLAST algorithm (Altshul et al., 1990) identified two ORFs from $S$. cerevisiae and one ORF from Schizosaccharomyces pombe as having significant homology. The ORFs SCYJL212C and YSCP9677 from S. cerevisiae were identified during the genome sequencing project and were not assigned any function. The remaining ORF, ISP4 from Schiz. pombe, was identified as a gene of unknown function that was up-regulated as a result of inducing meiosis through nitrogen starvation (Sato et al., 1994). However, whether this induction was meiosisspecific or due simply to nitrogen starvation was not determined. The predicted protein products of the putative homologues were aligned (Fig. 4) using the PileUp program (Feng \& Doolittle, 1987) from the Genetics Computer Group (GCG) software (Devereux et al., 1984) and percentage identity and similarity were calculated using the GCG program Bestfit. The protein Isp4p from Schiz. pombe exhibited the highest homology with $48 \%$ identity and $70 \%$ similarity. The two proteins from $S$. cerevisiae exhibited lower homology with $40 \%$ identity and $63 \%$ similarity for SCJL212C and 34\% identity and $59 \%$ similarity for YSCP9677.

The PTR family of peptide transporters is characterized by the signature motif FYXXINXGSLS (Steiner $e t$ al., 1995), whereas the $A B C$ transporters are characterized by the ATP-binding Walker motifs (Higgins, 1992). The predicted protein product of OPT1 did not contain the PTR signature motif or the ABC Walker motif. Furthermore, a comparison of OPT1 with the PTR di/tripeptide transporter CaPTR2 using the GCG program Bestfit revealed only $18 \%$ identity between the two transporters. These data indicated that OPT1 is not a member of the PTR or ABC families of membrane transporters.

\section{Peptides as growth substrates}

To determine the size constraints of peptide utilization mediated by pOPT1, we tested the ability of $S$. cerevisiae PB1X-9B (a mutant in the di-/tripeptide transporter) harbouring either pRS202 (the parent vector) or pOPT1 (pRS202 containing the $3.8 \mathrm{~kb}$ insert with the OPT1 gene) to grow on KL, KLG, KLLG and KLLLG as a sole source of leucine. Previously it has been shown that di/tripeptide transport activity in C. albicans and $S$. cerevisiae is regulated by nitrogen: rich nitrogen sources such as ammonium sulfate repress transport, while poor 
GATCATGTGGCTAAAAATTCATATGGCTTTATGCTGTGGCTTCAGCTCTACTGATAATTGATATCTTTATT CCTATACATAAATATTAAAGCCACTTGATTATTGCTCATAGGGCCAAAAAAACAAAAAGATGCAGAACCATCTAAAGTTTTGTTTTGTGTTTGCTATT TTGTGCCTAGTGAGATTAAATTAGTTATCTTTTCATGACAAAAATCCTTTAGACTACTTTTTATTCCATTTGTTTGGTTTACGATTATCAATCGTCAT AGTTCAATTTGTAAAATTTTATCTTTTCAATCCCAAACCTTTTAAATAGTCAGTAATTTCTCTCATAGGAATTTCAAGTTTCCACTTTTTTTTGTCTT CCTTCTATTTTCTTTTTATAAGTTTACTGTTTCGTGAAATATTATTCATTTGTATTATTTTTACTAAGTCAACCACTATTGATTCCATTCCTAACACT TATTATAAGTACTTACT

ATG GAC AAA ATA AGg GCA GTA ATT AGT GGA GGT GAG AAA CCT CCC GTT GAC ACT GAC AAC GAT CAC AAC ACA GAC

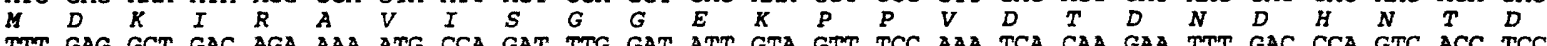

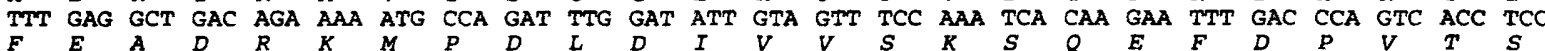

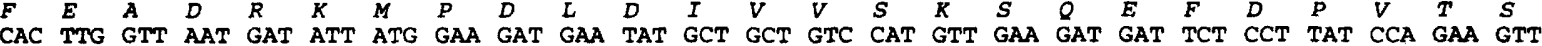
$\begin{array}{lllllllllllllllllllllllll}H & L & V & N & D & I & M & E & D & E & Y & A & A & V & H & V & E & D & D & S & P & Y & P & E & V\end{array}$ AGA GCA GCT GTT CCT TCT ACT GAC GAC CCA ACT TTA CCT CAA AAT ACC ATT AGA GCC TGG GTT ATT GGT TTG ATA

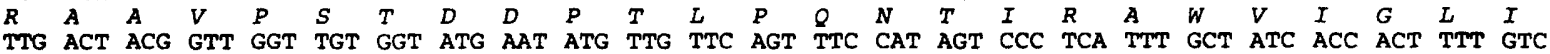

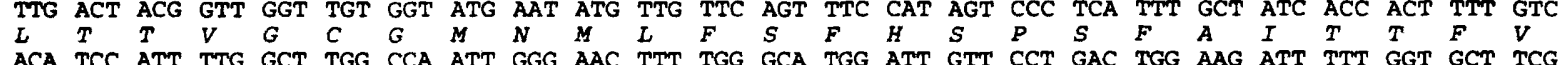
ACA TCC ATT TTG GCT TGG CCA ATT GGG AAC TTT TGG GCA TGG ATT GTT CCT GAC TGG AAG ATT TTT GGT GCT TCG TTA AAT CCA GGT CCA TTC AAC GTT AAA GAA CAT ACT ATC ATC ACT ATT ATG GCC AAC GTT TCT TTT GGT ACT GGT

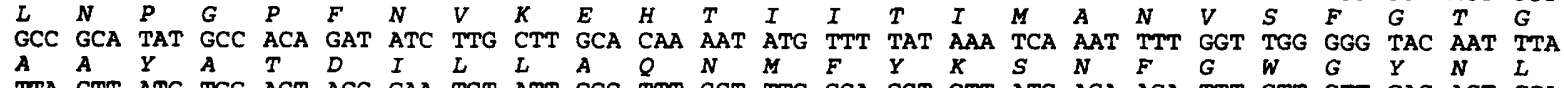

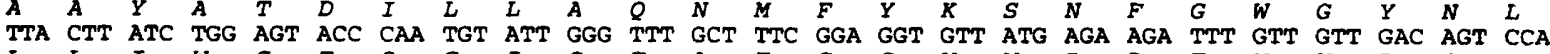

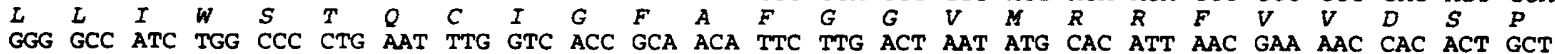

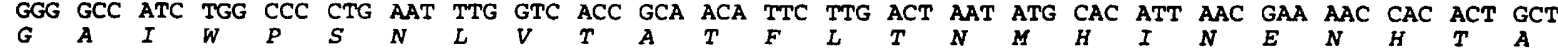

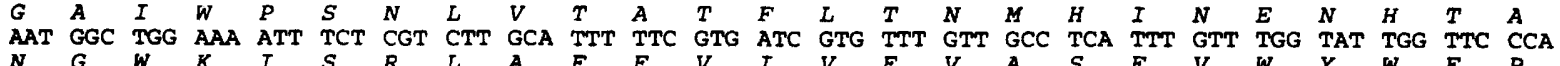

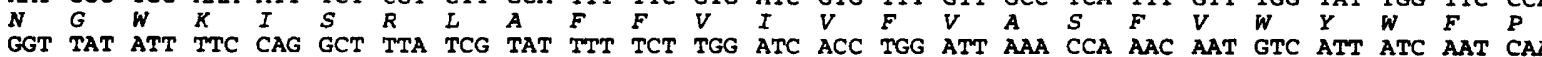

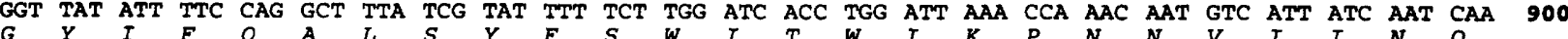

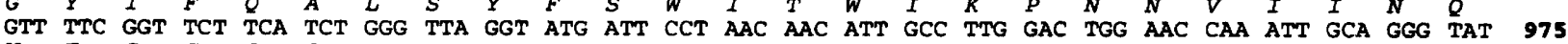

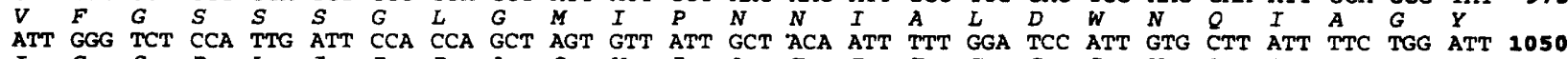

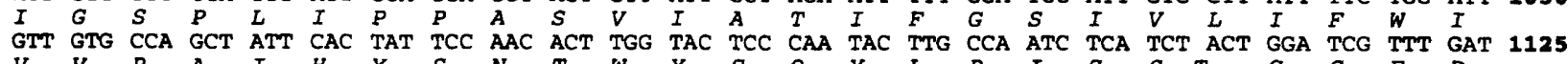

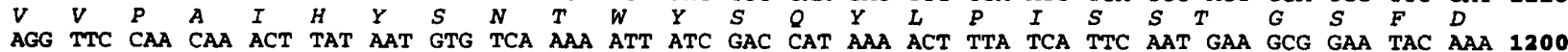

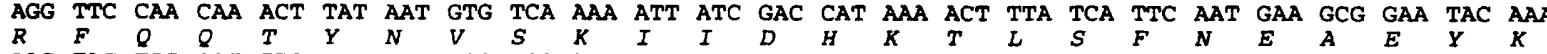

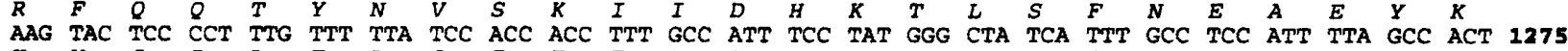
$\begin{array}{lllllllllllllllllllllllll}K & Y & S & P & L & F & L & S & T & T & F & A & I & S & Y & G & L & S & F & A & S & I & L & A & T \\ \end{array}$ ATA ACA CAC ACC ATT TGC TTC CAT GGA CGT GAC CTT ATC GCA TCG TIG AAG GCC AAA GAA AAA CCA GAT GTT CAC 1350

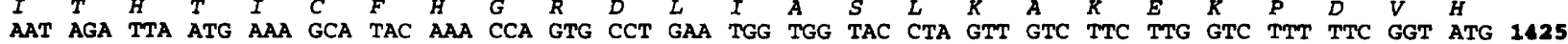

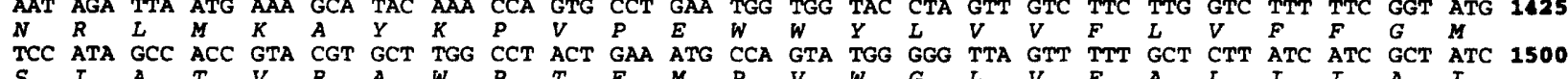

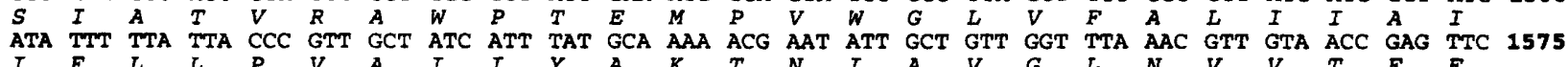

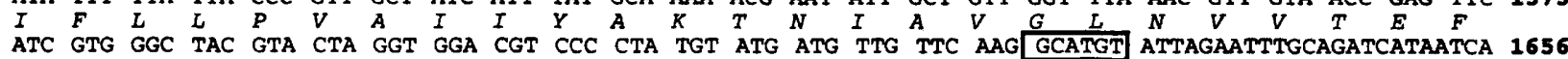
ATC GTG GGC TAC GTA CTA GGT GGA CGT CCC CTA TGT ATG ATG TTG TTC AAG

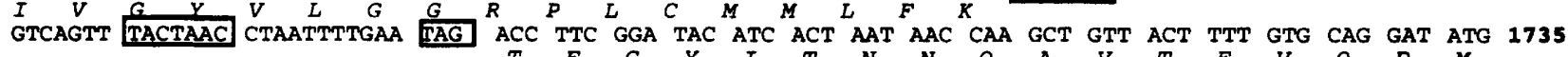
AAA CTT GGG CAC TAC ATG AAA ATA GAT CCG CGC ACT TTE TTT TGG GCG CAG TTT GCT GCT ACC ATA TGG GGA TCG

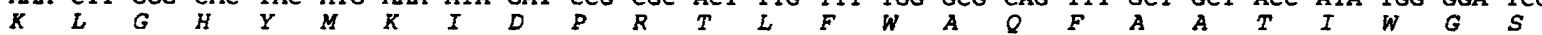

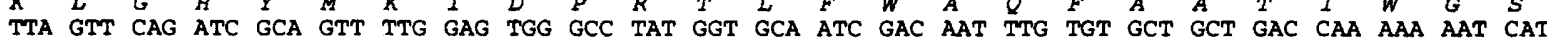

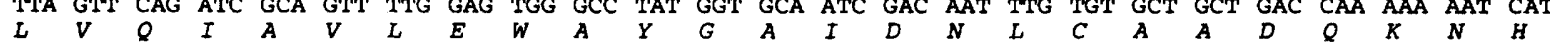
TAC ACA TGT CCA AAC GGT AAA GTT TTC TTC AAT GCT TCG ATC ATT TGG GGT GTC ATT GGA CCC CAA CGT CAA TTC

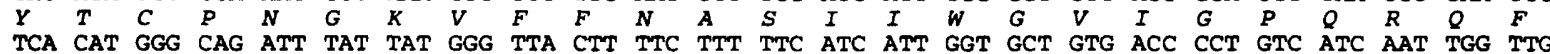

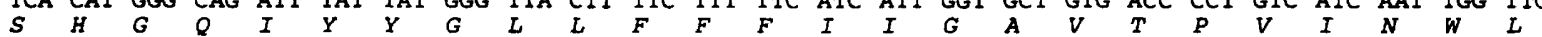

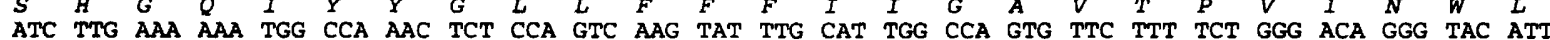

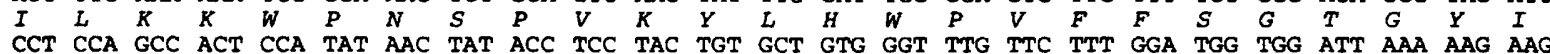

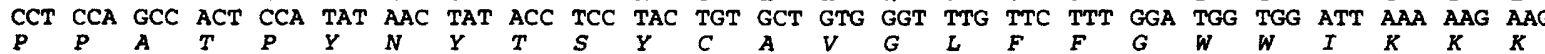

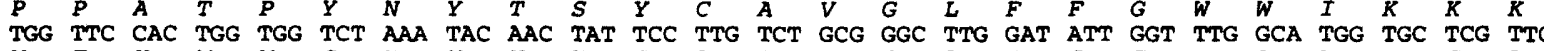

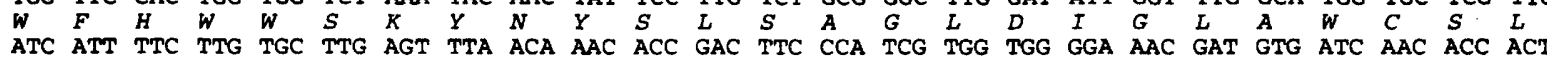

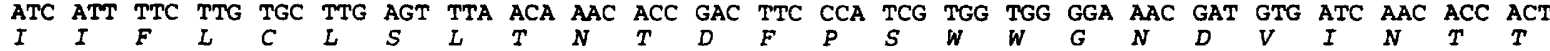

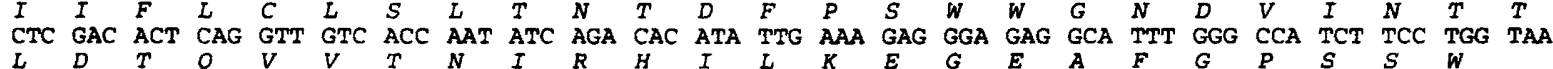

GCTGACGAAGAAACACACACACACACATTATTGCTTCCTATTGTCGTGTCTTTTATGTAGATGTAACGTGTTTTTATAAGAATGTAATTTAATTATTGT ATATATATGCCAAATATTTTTACTGCCATTTTATATTCTTTCTGCCACTAAAAATGATAGGAGGTTTTGTATACTGGGTGTGCTTGTTTTACACGCGG CTCTTTTATTATTGATTTGAACAGTCTCTAAGGAAGTTACGAACTTATAGGTGAGTGCTAAAAATGAAAAGGGGGTGAGGTTCCTTCTTATATCCTTT TTGGCAAGTAAATGTGTCGTGCTTTGATATATTAGAAAGACAATCCATTAATAGATGAAATATATATTGATGATGAAAAAAGTATTGGTTGTTCAAAAT GAAAGATCAATATAAAAATTCGGAGAGAAACGTGATGTTTATAGAGTAAAAAATTGAGCTGATAACTTCGCAACCAATTCTGAACAAGCATAGTTTGCA AATATGAATACATCCTAGAAAAAGTGTAATCTATGAGGAAATATGCAGGATATTCATGATCTCTIAGCAAAATATTAAGGTTCAATCGGTTTTGTGATT GGTTGCAAAATTTATCATTCGCGGTGTAAGTACACCAAGAAGTTAGACACCTACATGATCTTTTTTTGTTTTTTCAATTCTTTTGATTTCCTATAAAAGT TCTCCCGTTTTCCTTTCCTTTCTTTTCTGAAAATGAACAATATAGAATATCTTTTTTTGGTGAAATCACTGATTGCCTAACCTTCGTTCTTGAATTTAT ATTCTATTAATATTGTTGTATCATCGCTGCTTCATTTCCATTCCTTCTGTTTCAAAATCAAATATAAAAAGTTCAAAGAATGATCAATAGTGACAATTT TCAAGCTCGTGTAAACTGTGAAAGTAATACAAGACTCTGCAGAATACACATGCTGAAAATAATTAATGACAAAGGTATGTTGAACATGATC

Fig. 3. Nucleotide and predicted amino acid sequences of OPT1. The predicted amino acids are italicized and numbered to the left of the figure while nucleotides are numbered to the right. The $5^{\prime}$ and $3^{\prime}$ splice sites as well as the conserved branch point of the intron are boxed. The codon CUG (CTG in the DNA) encodes serine not leucine in C. albicans (Omaha et al., 1993). 


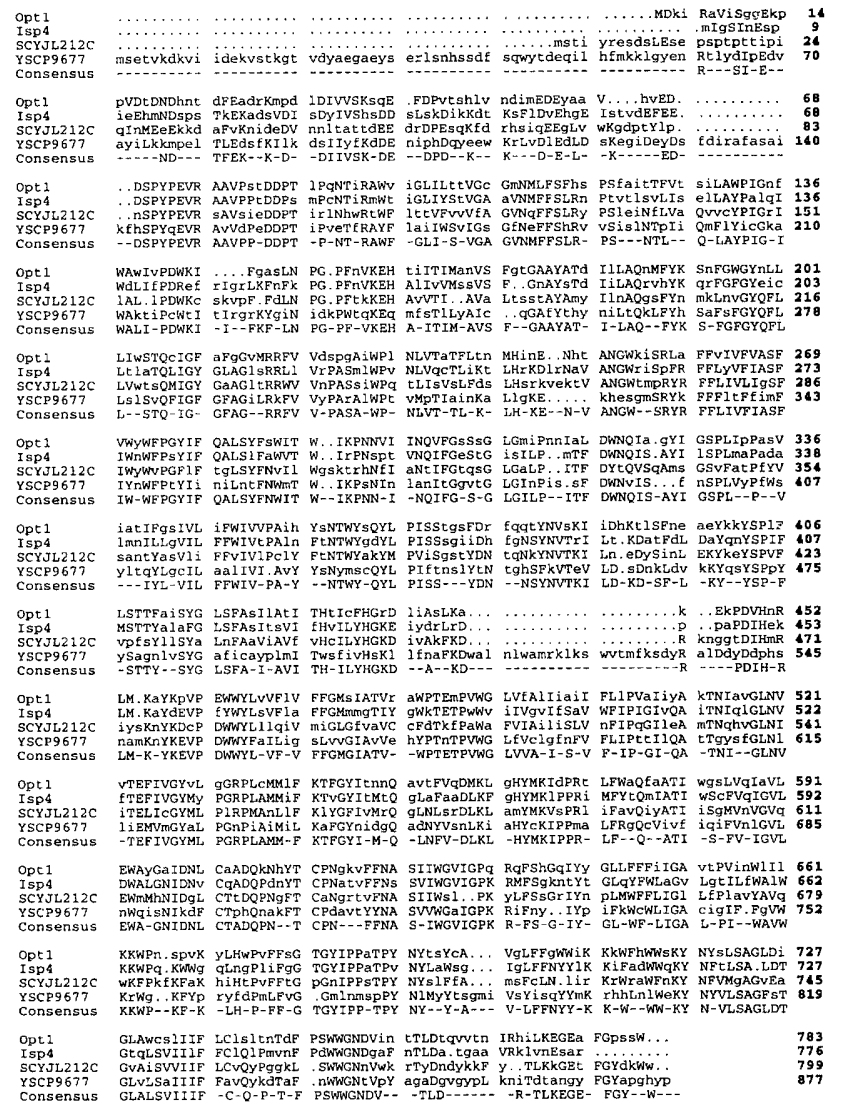

Fig. 4. Comparison of oligopeptide transporters. The proteins Opt1, Isp4, SCYJL212C and YSCP9677 were aligned using the program PileUp. Conserved residues are in upper case and denoted as the consensus, while nonconserved residues are in lower case. The amino acids in each respective protein are numbered to the right. nitrogen sources such as proline derepress transport. Therefore, we simultaneously determined the effect of nitrogen source on oligopeptide transport activity by supplying either ammonium sulfate or proline as the nitrogen source. When grown on a medium containing ammonium sulfate, PB1X-9B(pOPT1) was only able to utilize the peptide KLLG as a source of leucine whereas PB1X-9B(pRS202) did not utilize any of the peptides tested. When grown on a medium containing $0 \cdot 1 \%$ proline, PB1X-9B(pOPT1) was also able to utilize the tetrapeptide KLLG as a sole source of leucine, although the growth was much more robust than the growth on the ammonium sulfate medium. No growth was observed on KL, KLG and KLLLG for PB1X-9B(pOPT1) or PB1X-9B(pRS202).

\section{Sensitivity of S. cerevisiae transformants to toxic peptides}

S. cerevisiae $\mathrm{PB} 1 \mathrm{X}-9 \mathrm{~B}$ is sensitive to the toxic amino acid ethionine but is resistant to ethionine-containing di-, tri-, tetra- and pentapeptides. We used disk sensitivity assays to determine if cells transformed with pOPT1 were sensitive to toxic peptides and whether this sensitivity was dependent upon the nitrogen source. In those conditions where ammonium sulfate was used as a nitrogen source, no zone of growth inhibition was seen for the transformed strain in the presence of AEth, LEth or KLEth, whereas a $33 \mathrm{~mm}$ zone of inhibition was seen for ethionine alone (Table 1). A small and diffuse zone of growth inhibition (about 11-15 mm) was seen for KLLEth, KLAEth and KLLAEth. When $0 \cdot 1 \%$ proline was used as a nitrogen source, a zone of complete growth inhibition was seen for the toxic peptides KLLEth, KLAEth and KLLAEth for PB1X-9B(pOPT1) but not for PB1X-9B(pRS202) (Fig. 5; Table 1). Neither strain exhibited sensitivity to the toxic dipeptide or

Table 1. Sensitivity of $S$. cerevisiae PB1X-9B transformants to various ethioninecontaining peptides

A total of $0.38 \mu \mathrm{mol}$ was spotted on a $6 \mathrm{~mm}$ disk placed on a lawn of cells. Each test comprised three or more independent assays and the results represented in the Table are means of the values obtained. Maximum variation between the zones of inhibition for each test was $\leqslant 3 \mathrm{~mm}$. None, no growth inhibition.

\begin{tabular}{|llllllll|}
\hline $\begin{array}{l}\text { S. cerevisiae } \\
\text { transformants* }\end{array}$ & $\begin{array}{c}\text { Nitrogen } \\
\text { source }\end{array}$ & & \multicolumn{5}{c}{ Zone of inhibition (mm) } \\
\cline { 3 - 7 } & & Eth & AEth & KLEth & KLLEth & KLAEth & KLLAEth \\
\hline pRS202 & $\left(\mathrm{NH}_{4}\right)_{2} \mathrm{SO}_{4}$ & 33 & None & None & None & None & None \\
pOPT1 & $\left(\mathrm{NH}_{4}\right)_{2} \mathrm{SO}_{4}$ & 33 & None & None & Diffuse & Diffuse & Diffuse† \\
pRS202 & Proline & 33 & None & None & None & None & None \\
pOPT1 & Proline & 35 & None & None & 32 & 34 & $32 \ddagger$ \\
\hline
\end{tabular}

* Transformants tested harboured either the parent vector (pRS202) or pRS202 containing the $3.8 \mathrm{~kb}$ fragment (pOPT1).

† A small and diffuse halo with no distinct zone of growth inhibition was observed.

$\ddagger$ The halo observed was hazy. 

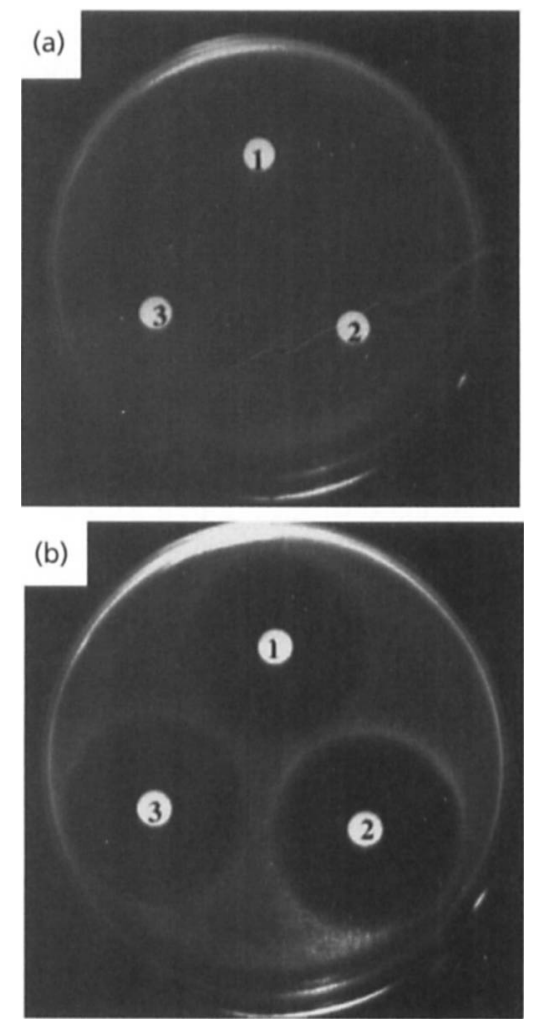

Fig. 5. Toxic peptide inhibition assay. Sensitivity to the ethionine-containing peptides KLLAEth (1), KLAEth (2) and KLLEth (3) on a $0.1 \%$ proline medium was determined as described in Methods. (a) PB1X-9B(pRS202); (b) PB1X9B(pOPT1).

tripeptide AEth and KLEth when proline was used as a nitrogen source.

\section{Transport of KLG-[ $\left[{ }^{3} \mathrm{H}\right] \mathrm{L}$ in S. cerevisiae transformants}

To determine if $S$. cerevisiae transformants harbouring pOPT1 could accumulate a radiolabelled tetrapeptide, uptake assays were performed with the radiolabelled substrate KLG- $\left[{ }^{3} \mathrm{H}\right] \mathrm{L}$ with cells grown to exponential phase in SC-Ura with either ammonium sulfate or $0 \cdot 1 \%$ proline as a nitrogen source. PB1X-9B(pOPT1) grown in SC with ammonium sulfate exhibited a significant uptake rate compared to no uptake by PB1X9B(pRS202) (Fig. 6a). Furthermore, PB1X-9B(pOPT1) demonstrated a higher initial rate of uptake when compared to C. albicans SC5314 grown in the same medium. This higher initial rate can be explained by overexpression due to high copy number or alternatively by the lack of requisite regulatory elements which may be absent in the heterologous host. All three strains had a higher rate of initial uptake when grown in SC-Ura with $0.1 \%$ proline as a nitrogen source (Fig. 6 b). PB1X9B(pRS202) did accumulate the tetrapeptide KLGL under these conditions but apparently not to a large enough extent to support growth on KLLG or to exhibit sensitivity to KLLEth or KLAEth (Table 1; Fig. 5).

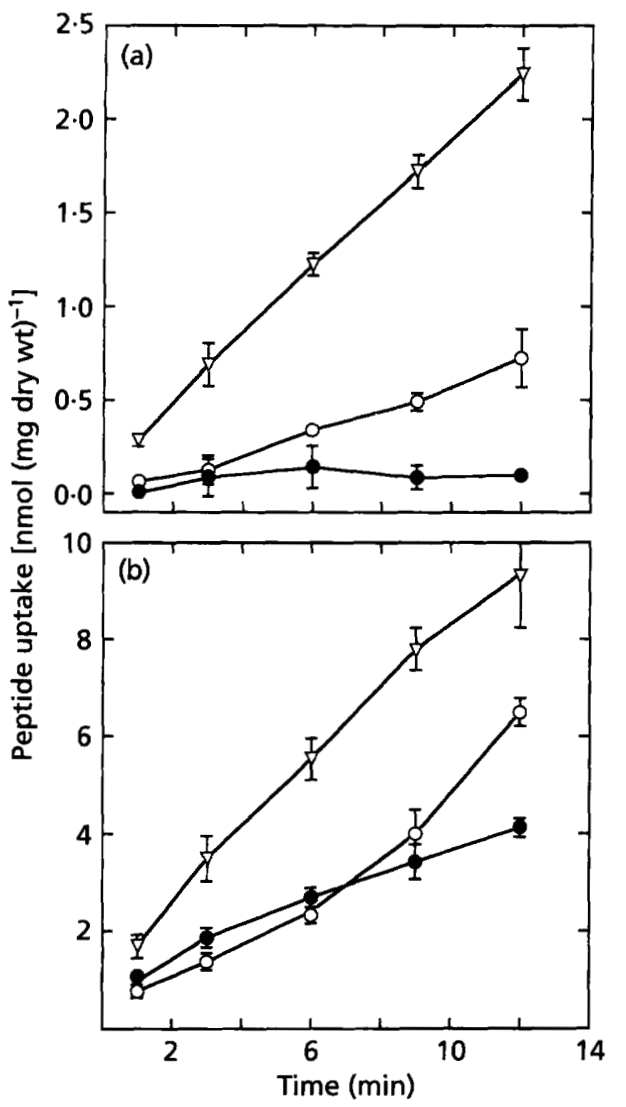

Fig. 6. Peptide transport assay. Accumulation of KLG-[3H]L was measured over a 12 min time course as described in Methods. $S$. cerevisiae PB1X-9B harbouring pRS202 (O) or pOPT1 $(\nabla)$ and $C$. albicans SC5314 (O) were grown in SC-Ura medium with either ammonium sulfate (a) or $0.1 \%$ proline (b) as a nitrogen source.

To more rigorously determine the size constraints of the oligopeptide transporter, the accumulation of KLG$\left[{ }^{3} \mathrm{H}\right] \mathrm{L}$ was measured in the presence of a 10 -fold molar excess of the competitors L, KL, KLG, KLLG and KLLLG. SC-Ura with ammonium sulfate was chosen as the growth medium because under these growth conditions PB1X-9B(pOPT1) accumulated KLG- $\left[{ }^{3} \mathrm{H}\right] \mathrm{L}$ whereas PB1X-9B(pRS202) did not (Fig. 6a). As seen in Fig. 7, L and KL do not compete with the uptake of KLG- $\left[{ }^{3} \mathrm{H}\right] \mathrm{L}$ whereas competition was seen with KLLG and KLLLG. The tripeptide KLG exhibited decreased competition in comparison to KLLG or KLLLG (Fig. 7), possibly due to a lower affinity, although this low level of KLG uptake is below the threshold to support full growth when used as an auxotrophic supplement. Uptake rates were calculated from a best-fit of the slope for each set of data. The uptake rate of KLG- $\left[{ }^{3} \mathrm{H}\right] \mathrm{L}$ in the presence of no competitor, $\mathrm{L}$ or $\mathrm{KL}$ was $0.24,0.25$ and $0.26 \mathrm{nmol} \mathrm{min}{ }^{-1}$ ( $\mathrm{mg}$ dry weight $)^{-1}$, respectively. When KLG was used as a competitor, the uptake rate was $0.12 \mathrm{nmol} \mathrm{min}^{-1}$ (mg dry weight) ${ }^{-1}$, which was approximately $50 \%$ of the no competitor rate. The uptake rate approximated zero when KLLG and KLLLG were used as competitors. 


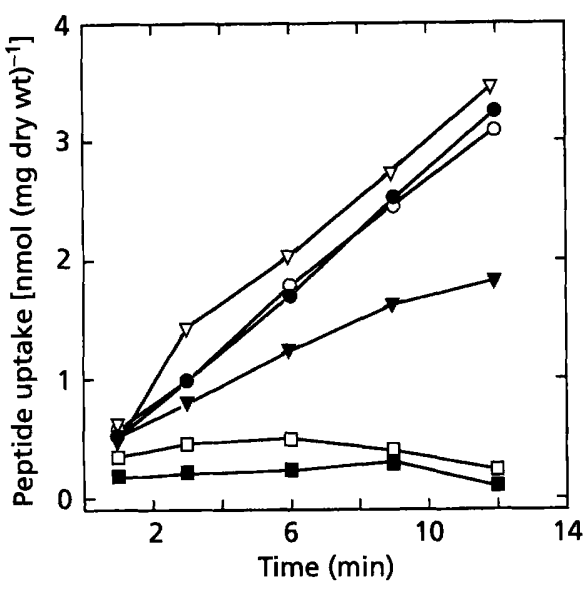

Fig. 7. Peptide transport competition experiment. Accumulation of KLG- $\left[{ }^{3} \mathrm{H}\right] \mathrm{L}(\mathrm{O})$ was measured in the presence of a 10-fold molar excess of the competitors $L(O), K L(\nabla), K L G$ $(\nabla)$, KLLG ( $\square$ ) or KLLLG $(\boldsymbol{\square})$ over a 12 min time course.

\section{DISCUSSION}

Three lines of evidence support the cloning of an oligopeptide transport gene from C. albicans. First, the plasmid pOPT1 conferred the ability to utilize the peptide KLLG to satisfy the leucine auxotrophic requirement of $S$. cerevisiae PB1X-9B when grown on a medium with a rich or poor nitrogen source. Secondly, the $S$. cerevisiae strain PB1X-9B was not sensitive to the toxic peptides KLLEth, KLAEth or KLLAEth when grown on a minimal medium with $0.1 \%$ proline as a nitrogen source but was sensitive when transformed with pOPT1 (Fig. 5; Table 1). Similarly, a very faint zone of growth inhibition was seen for KLLEth, KLAEth and KLLAEth when PB1X-9B(pOPT1) but not PB1X$9 \mathrm{~B}$ (pRS202) was grown in a medium containing ammonium sulfate. Finally, PB1X-9B(pRS202) had an initial uptake rate of zero for the radiolabelled substrate KLG- $\left[{ }^{3} \mathrm{H}\right] \mathrm{L}$ when grown on a medium containing ammonium sulfate whereas PB1X-9B(pOPT1) had a dramatically higher initial uptake rate (Fig. 6a). When the growth medium contained proline as a nitrogen source, the initial uptake rate was 2.5 times higher for PB1X-9B(pOPT1) than for PB1X-9B(pRS202) (Fig. 6b). Furthermore, KLLG and KLLLG and to a lesser degree KLG competed with the uptake of KLG- $\left[{ }^{3} \mathrm{H}\right] \mathrm{L}$ (Fig. 7). The fact that leucine did not compete with KLG- $\left[{ }^{3} \mathrm{H}\right] \mathrm{L}$ for uptake excluded the possibility that OPT1 encoded a secreted protease. Therefore, we propose that we have cloned an oligopeptide transporter from C. albicans capable of transporting tetra- and pentapeptides and, to a lesser extent, tripeptides.

The predicted protein product of OPT1 did not show any significant homology to any members of the $A B C$ superfamily or PTR family of transporters. Furthermore, a search of the Prosite (Bairoch, 1992) and Motifs (Devereux et al., 1984) databases for protein motifs did not reveal any previously identified functional domains common to transport proteins with the exception of potential glycosylation sites. However, the 12 putative transmembrane domains separated by hydrophilic regions as well as the expression of transport activity in a heterologous host are suggestive of an integral membrane transporter. Because three ORFs of significant homology as well as several expressed sequence tags (data not shown) were identified, the possibility exists that OPT1 constitutes the first identified member of a new family of transporters. We are currently testing this hypothesis in our laboratory by testing these ORFs for oligopeptide transport activity.

Opt1p is able to accommodate peptides of three to five residues; peptides of larger than five residues were not tested. As demonstrated by growth assays, halo assays and competition experiments, tetrapeptides were most readily transported by Opt1p. Pentapeptides did enter the cell as demonstrated by sensitivity to KLLAEth and supported by the competition between KLLLG and KLG- $\left[{ }^{3} \mathrm{H}\right] \mathrm{L}$. However, KLLLG was not able to support growth when used as a source of leucine, possibly due to the inability of cellular peptidases to release leucine from this peptide. Similarly, KLG was able to compete slightly with KLG- $\left[{ }^{3} \mathrm{H}\right] \mathrm{L}$ for entry into the cell, but KLG did not support growth and KLEth was not toxic. Because the number of possible tri- and pentapeptides is large and our sample size small, we cannot conclude that Opt1p has a lower affinity for tri- and pentapeptides than for tetrapeptides.

Sequence analysis revealed the presence of a 58 nucleotide intron located within the $3^{\prime}$ half of OPT1. The $5^{\prime}$ splice site, $3^{\prime}$ splice site and branch point are identical to previously reported type II introns within fungi (Rymond \& Rosbash, 1992). It is interesting to note that the di-/tripeptide transporter CaPTR2 also contains a small type II intron that is located within the $3^{\prime}$ half of the gene. It has been suggested that introns play a regulatory role. However, a comparison of the two introns did not reveal any apparent consensus sequences that might be suggestive of a common regulatory element or of a common ancestry.

To date, only one study has been published addressing the regulation of oligopeptide transport activity in $C$. albicans. Basrai et al. (1992) concluded that sensitivity to toxic oxalysine-containing tetra- and pentapeptides was not influenced by the nitrogen source or by the presence of amino acid inducers. However, our findings suggest that when expressed in $S$. cerevisiae, OPT1 is regulated by the nitrogen source. The discrepancy in the results may be explained by differences in the levels of regulation or substrate specificity between the two different strains used in the studies or, alternatively, by superimposition of a $S$. cerevisiae regulatory mechanism on the CaOPT1 gene expressed heterologously.

A search of the database using the BLAST algorithm identified three putative homologues of OPT1. The ISP4 gene from Schiz. pombe exhibited the highest homology and was identified by Sato et al. (1994) through a subtractive hybridization experiment using RNA iso- 
lated from nitrogen-starved and non-nitrogen-starved cells. In Schiz. pombe, nitrogen starvation induces meiosis and therefore this nitrogen-starvation/meiosisinducing screen identified genes that were either induced during meiosis or regulated by the nitrogen catabolite repression system. Based upon the high homology between OPT1 and ISP4 and the established role of nitrogen regulation in many peptide transport systems, we hypothesize that ISP4 encodes an oligopeptide transporter that is regulated by the nitrogen source. The remaining two putative homologues were from $S$. cerevisiae and were identified during the genome sequencing project. Interestingly, few favourable conditions have been identified for oligopeptide transport activity in S. cerevisiae. As seen in Fig. 6, when PB1X$9 \mathrm{~B}$ (pRS202) was grown in a medium containing proline it exhibited an initial KLG- $\left[{ }^{3} \mathrm{H}\right] \mathrm{L}$ uptake rate that was comparable to the initial uptake rate in PB1X9B(pOPT1) when grown in a medium with ammonium sulfate. However, under these conditions PB1X9B(pRS202) exhibited no sensitivity to the toxic tetrapeptides KLLEth and KLAEth and was not able to utilize the tetrapeptide KLLG as a sole source of leucine, whereas PB1X-9B(pOPT1) did grow on KLLG and exhibited slight sensitivity to the toxic peptides KLLEth and KLAEth. This discrepancy in results could be explained by an uptake rate exhibited by PB1X9B(pRS202) that may not necessarily be reflective of total peptide accumulation over the prolonged incubation times necessary for growth and sensitivity assays. We are currently trying to determine if these two putative $S$. cerevisiae OPT 1 homologues are responsible for this low-level oligopeptide transport activity.

In summary, we report the cloning of a second peptide transport gene from $C$. albicans through heterologous expression in $S$. cerevisiae. The existence of multiple peptide transport systems has been documented extensively in both prokaryotes and eukaryotes. The redundancy of this phenomenon underscores its importance. With the identification of two peptide transport genes in C. albicans, CaPTR2 and now OPT1, the role of peptide transport in virulence, induction of secreted acid proteinases and cell wall recycling can now be explored in greater detail.

\section{ACKNOWLEDGEMENTS}

This work was supported by a grant from the American Cancer Society BE-39D, and a grant from the PSC-CUNY Research Award Program. We gratefully acknowledge Dr Gerry Fink for providing the C. albicans genomic library, Larry Zhang for peptide synthesis, David Barnes, Melinda Hauser and Jeff Wiles for helpful suggestions, Keith Henry for computer assistance, and Aaron Burchfield and Melissa York for technical assistance.

\section{REFERENCES}

Altshul, S. F., Gish, W., Miller, W., Myers, E. W. \& Lipman, D. J. (1990). Basic local alignment search tool. J Mol Biol 215, 403-410.

Ausubel, F. M., Brent, R., Kingston, R., Moore, D. D., Seidman, J.
G., Smith, J. A. \& Struhl, K. (1990). Current Protocols in Molecular Biology, 2nd edn. New York: Wiley Interscience.

Bairoch, A. (1992). PRosITE: a dictionary of sites and patterns in proteins. Nucleic Acids Res 20, 2013-2018.

Basrai, M. A., Zhang, H.-L., Miller, D., Naider, F. \& Becker, J. M. (1992). Toxicity of oxalysine and oxalysine-containing peptides against Candida albicans: regulation of peptide transport by amino acids. J Gen Microbiol 138, 2353-2362.

Basrai, M. A., Lubkowitz, M. A., Perry, J. R., Miller, D., Krainer, E., Naider, F. \& Becker, J. M. (1995). Cloning of a Candida albicans peptide transport gene. Microbiology 141, 1147-1156.

Becker, J. M. \& Naider, F. (1995). Fungal peptide transport as a drug delivery system. In Peptide Based Drug Design: Controlling Transport and Metabolism, pp. 369-384. Edited by M. Taylor \& G. Amidon. Washington, DC: American Chemical Society.

Christianson, T. W., Sikorski, R. S., Dante, M., Shero, J. H. \& Heiter, P. (1992). Multifunctional yeast high copy number shuttle vectors. Gene 110, 119.

Cundell, D. R., Pearce, B. J., Sandros, J., Naughton, A. M. \& Masure, H. R. (1995). Peptide permeases from Streptococcus pneumoniae affect adherence to eukaryotic cells. Infect Immun 63, 2493-2498.

Devereux, J., Haeberli, P. \& Smithies, O. (1984). A comprehensive set of sequence analysis programs for the VAX. Nucleic Acids Res 12, 387-395.

Feng, D.-F. \& Doolittle, R. F. (1987). Progressive sequence alignment as a prerequisite to correct phylogenetic trees. J Mol Evol 25, 351-360.

Fonzi, W. A. \& Irwin, M. Y. (1993). Isogenic strain construction and gene mapping in Candida albicans. Genetics 134, 717-728.

Gietz, D., Andrew, J., Woods, R. \& Schiestl, R. (1991). Improved methods for high efficiency transformation of intact yeast cells. Nucleic Acids Res 20, 1425.

Goshorn, A. G. \& Sherer, S. (1989). Genetic analysis of prototrophic natural variants of Candida albicans. Genetics 123, 667-673.

Hagting, A., Kunji, E. R., Leenhouts, K. J., Poolman, B. \& Konings, W. N. (1994). The di- and tripeptide transport protein of Lactococcus lactis: a new type of bacterial peptide transporter. J Biol Chem 269, 11391-11399.

Higgins, C. F. (1992). ABC transporters: from microorganisms to man. Annu Rev Cell Biol 8, 67-113.

Island, M. D., Naider, F. \& Becker, J. M. (1987). Regulation of dipeptide transport in Saccharomyces cerevisiae by micromolar amino acid concentrations. J Bacteriol 169, 2132-2136.

Island, M. D., Perry, J. R., Naider, F. \& Becker, J. M. (1991). Isolation and characterization of $S$. cerevisiae mutants deficient in amino acid-inducible peptide transport. Curr Genet 20, 457-463. Liu, H., Kohler, J. \& Fink, G. (1994). Suppression of hyphal formation in Candida albicans by mutation of a STE12 homolog. Science 266, 1723-1725.

McCarthy, J. P., Nisbet, L. J., Boehm, J. C. \& Kingsbury, W. D. (1985). Multiplicity of peptide permeases in Candida albicans: evidence from novel chromophoric peptides. J Bacteriol 162, 1024-1029.

Milewski, S., Andruskiewicz, R. \& Borowski, E. (1988). Substrate specificity of peptide permeases in Candida albicans. FEMS Microbiol Lett 50, 73-78.

Omaha, T., Suzuki, T., Mori, M., Osawa, S., Ueda, T., Watanabe, K. \& Nakase, T. (1993). Non-universal decoding of the leucine 
codon CUG in several Candida species. Nucleic Acids Res 21, 4039-4045.

Parra-Lopez, C., Baer, M. T. \& Groisman, E. A. (1993). Molecular genetic analysis of a locus required for resistance to antimicrobial peptides in Salmonella typhimurium. EMBO J 12, 4053-4062.

Payne, J. W. \& Shallow, D. A. (1985). Studies on drug targeting in the pathogenic fungus Candida albicans: peptide transport mutants resistant to polyoxins, nikkomycins and bacilysin. FEMS Microbiol Lett 28, 55-60.

Payne, J. W. \& Smith, M. W. (1994). Peptide transport by microorganisms. Adv Microbiol Physiol 36, 1-80.

Perry, J. R., Basrai, M. A., Steiner, H.-Y., Naider, F. \& Becker, J. M. (1994). Isolation and characterization of a Saccharomyces cerevisiae peptide transport gene. Mol Cell Biol 14, 104-115.

Rymond, B. C. \& Rosbash, M. (1992). Yeast pre-mRNA splicing. In The Molecular and Cellular Biology of the Yeast Saccharomyces, pp. 143-192. Edited by E. W. Jones, J. R. Pringle \& J. R. Broach. Cold Spring Harbor, NY: Cold Spring Harbor Laboratory.

Sambrook, J., Fritsch, E. F. \& Maniatis, T. (1989). Molecular Cloning: a Laboratory Manual, 2nd edn. Cold Spring Harbor, NY: Cold Spring Harbor Laboratory.

Sato, S., Suzuki, H., Widyastuti, U., Hotta, Y. \& Tabata, S. (1994). Identification and characterization of genes induced during sexual differentiation in Schizosaccharomyces pombe. Curr Genet 26, 31-37.
Sherman, F., Fink, G. R. \& Hicks, J. B. (1986). Methods of Yeast Genetics. Cold Spring Harbor, NY: Cold Spring Harbor Laboratory.

Smith, L. M., Sander, J. Z., Kaiser, R. J., Hughes, P., Dodd, C., Connel, C. R., Heiner, C., Kent, S. B. \& Hood, L. E. (1986). Fluorescence detection in automated DNA sequence analysis. Nature 321, 674-679.

Song, W., Steiner, H.-Y., Zhang, L., Naider, F., Stacey, G. \& Becker, J. M. (1996). Cloning of a second Arabidopsis peptide transport gene. Plant Physiol 110, 171-178.

Steiner, H.-Y., Song, W., Naider, F., Zhang, L., Becker, J. M. \& Stacey, G. (1994). An Arabidopsis peptide transporter is a member of a new class of membrane transport proteins. Plant Cell 6, 1289-1299.

Steiner, H.-Y., Naider, F. \& Becker, J. M. (1995). The PTR family: a new group of peptide transporters. Mol Microbiol 16, 825-834.

Ward, A. C. (1990). Single step purification of shuttle vectors from yeast for high frequency back-transformation into E. coli. Nucleic Acids Res 18, 5319.

Yadan, J. C., Gonneau, M., Sarthou, P. \& Le Goffic, F. (1984). Sensitivity to nikkomycin $\mathrm{Z}$ in Candida albicans: role of peptide permeases. J Bacteriol 160, 884-888.

Received 4 July 1996; revised 24 September 1996; accepted 25 September 1996. 